\title{
Consumer group calls for antidiabetes drug to be withdrawn
}

\begin{abstract}
A few errors made it into this News story by Jeanne Lenzer (BMJ 2012;344:e3259, doi:10.1136/bmj.e3259). In the second paragraph it should have read that Public Citizen's Health Research Group said that liraglutide is associated with higher than expected risks [not rates] of pancreatitis, thyroid cancer, and kidney failure. In the fourth paragraph the last sentence should have been: "The FDA [not she] also cited concerns about possible associations with thyroid and pancreatic cancer, kidney failure, and serious allergic reactions." Lastly, Sidney Wolfe's
\end{abstract}

comment that was quoted in the penultimate paragraph as "Novo Nordisk's ads make Victoza sound like it's a piece of cake since you can inject once a day instead of twice daily with insulin" should have been "Novo Nordisk's ads make Victoza sound like it's a piece of cake since you can inject just once a day."

Cite this as: BMJ 2012;344:e3370

๑ BMJ Publishing Group Ltd 2012 